Oann Tr. Aprooric Frvers. Cause: A specific poison derived from brute animals; communicable. Effect of poi$\mathrm{m}$ : Inflammation of the skin, and of the mucous membrane of the larynx; pharynx, mouth, and nose. The following six gener :-1. Glanders; 2. Malignant pustulo; 3. Boils (l); 4 . inrrain (diphtheritis); 5. Hydrophobis; 6. Tarantismus(?).

Ordar vir. Excremory Fevars. Cause: Retained urinary and cutaneous excreta, acting as poisons. Bffect of the poison: Bffusive and congestive inflammation of the derma, burse mucose, serous membranes, and sero-fibrous tissues.

Genus 1. The erythematic excretory ferers.

Species 1. Rheumatic ferer; inflammation of the serous and saro-fibrous tissues.

Species 2. Arthritic fever; inflammation of the skin, burse mucose, and sero-fibrous tissues.

Species 3. Erythema (nodosum etc.).

Genus 2. Rose rash fevers (the roseolø).

Genus 3. The nettle rash fevers.

Tenus 4. The bleb fevers.

Species 1. The herpes; herpes zoster (shingles), etc.

species 2. Pemphigus.

These several orders of fever may be thus grouped:-

Ordars I and II. Endemic; Orders III and IV. Epidemic ; Orders IV, V, vI. Domestic; Order vir. Diathetic. The endemic depend on locality; the epidemic are often communicable through the atmosphere; the domestic are communicable by contact; the diathetic are hereditary.

Sereral of these fever poisons induce chronic, congestive, and inflammatory diseases, instead of fevers. The poisons of the endemic, domestic, and diathetic orders, are of this kind. Thus, malaria induces splenic congestion and inflammation, chlorotic gastritis, local nervous diseases, etc.; ochlesis causes chronic bronchitis, pulmonary tuberculosis, etc. Several of these poisons combine with each other, and stand in the mutual relations of predisposing or exciting causes. This is especially to be observed in the malarious, miasmatic, and ochletic fevers. It is so frequent an occurrence, indeed, that it is rarely a fever occurs from one kind of poison only. Thus agues are frequently complicated with abdominal or fæcal affections; thus, also, malaria gives greater intensity to ochlesis, as in cholera, ship or camp typhus, etc. The predominant symptoms of a combining poison give what is termed the type to an epidemic or endemic fever; as when malaria combines with a large predominance of a fecal poison, the result is an intermittent, charactorised by intestinal symptoms, as diarrhcea, dysentery, cholera: hence choleraic and dysenteric tertians, etc.

By an endemic fever, I mean a fever restricted to the population of a given locality; by an epidemic fever, I mean a fever generally prevalent. Thus agues are endemic ; fecal fevers, infectious fevers, etc., epidemic. By the term infectious, I designate those fevers the specific poison of which commingles with the atmosphere, as well as with fluids (e.g., the secretions); by contagious fevers, I mean those the poisons of which commingle with the fluids, or are material, but are not miscible with the atmosphere. Contagious fevers may be endemic; infectious fevers, epidemic ; either, sporadic. By non-recurrent fevers, I mean those the poison of which, having once developed its appropriate phenomena in the living body, is thenceforward eliminated from the system as fast as it is formed or received, and so rendered harmless. Persons so eliminating the poison may, however, give off poisonous excretions from thoir skin, lungs, intestinal mucous surface, etc.; and thus be corrupting or morbific media, although themselves in bealth.

Much has jet to be ascertained regarding the aature and origin of febrific poisons; consequently, the abore nosological arrangement is arowedly submitted as an imperfect arrangement. The principle is, I believe sound, and will cenduce to the more accurate determination of the nature and origin.of fevers, by tracing them, as the nesults of toxic apouts, to their specific causes. It will imore especially aid in the iareatigntion of those ferers which aries, fram tro or no prisons in eombination; and will eaciet in the better. disgnosis and treatmont of those which, dependent upon a specific poison, have nevertheless their symptoms modified and their true nature hid by the action of complicating fever poisons.

Yort, July 25th, 1855.

\section{CASES OF TRAUMATIC TETANUS SUCCESSFULLY TREATED.}

By CHARLES COWDELL, M.D.Lond., Physician to the Dorset County Hospital, Dorchester.

[Read, in brief, at the Anniversary Meeting of the Dorset Branch, at Sherborne, Dorset.]

MANY recognised views of pathology and therapeutics are undergoing a severe scrutiny; and new and more powerful means of investigation are now brought to bear upon them. How much more, then, does it behove every practitioner to record his experience on any of the yet disputed questions which render the science and practice of modicine 80 inexact and uncertain.

Scarcely any disease has been more empirically treated than tetanus. In the hands of medical men, taking varying, and indeed opposite, views of its pathology, it has been treated antiphlogistically, by bleeding, purgatives, mercury, and local application of cold, or blistering the spine; or, per contra, by conics, quinine, muriated tincture of iron, etc.; or, thirdly, by narcotics, tobacco, opium, Indian hemp (cannabis Indica), etc.; no two practitioners of eminence agreeing as to its nature or necessary treatment. It was at last hoped by many sanguine persons that the discovery of the anæsthetic properties of æther and chloroform would wipe out the opprobrium under which we lay in regard to this dreadful disease; but this method, like its predecessors, has disappointed our expectations.

In regard to the pathology and etiology of tetanus, there is of course as much disagreement. Congestion of the spinal cord (inflammatory in some cases) has been perhaps the most commonly adopted expression of its pathology; and the high authority of Rokitansky would go far to induce a belief in its reality. He says : "It is almost constantly met with in those cases, combined with an equal degree of congestion of the brain." (English edition, rol. iii, p. 448.) But I should conceive that this congestion is itself secondary, being the result of irritation; just, 28 in the irritation of the web of a frog's foot with the point of a needle or a medicinal irritant, you get congestion immediately set up.

Of the etiology of tetanus we know positively nothing. It will oecur after the most trivial injury, unattended with even the merest abrasion of surface; and, where a wound does exist, in every possible condition of such wound. It would therefore appear that there must be a morbid condition which strongly predisposes to this disease-a condition which indeed bears about the same proportion in the fully developed attack, as, in siege operations, is barne by the well charged mine in an explosion; the application of a match being alone requisite to produce the result: 80 an unrecognisable and undefinable irritation of the branches of peripheral nerves is, in a predisposed person, the match which explodes the accumulated combustibles, in store for this result.

We hope ere long the same pains will be bestowed on this subject as have so lately been applied by Dr. Routh.in the elucidation of pneumonia and its treatment, as contained in his recent communication to the Assocrurior JoURXAI an example eminently worthy of imitation.

Heving given the fullest trial to the method of treatroent by chloroform, with ice applied along the spine, and full support by beef-tea and sherry-a plan full of promise, and sanctioned by the hopeful recommendation of Dr. Todd; and this trial, moreover, having been made on a good subject in private practice, young, healthy, and affected by symptomas not over-ecuto - the chloroform vactly mitignting suffecins, and most infallibly abating spasm on overy iphalationseo 
much as to ensble us to give abundant nourishment by the mouth; and having, notwithstanding these favourable conditions, seen the disease proceed to a fatal termination,-I determined, on the occasion of $\mathrm{my}$ being called to another cos of tetanus, not to repest the trial. In this unsuccessful case, it should be mentioned that mercury had been given freely in its early stage, and ptyalism was established during the course of the malady; but without any apparent effect upon it beyond annoying the poor patient with constant claims for spitting out foetid saliva, which he had little ability to effect, and of course an additional draft upon his strength.

CA8E I. Feb. 5th, 1852. Mr. G. J., a farmer on a large scale, aged 28 years, single, and previously enjoying good health, living in a valley cultivated as water meadow, in the trial of a new implement, got the fingers of his left hand (three of them) very much crushed. Portions of the crushed fingers were at once removed, and the remaining parts dressed.

Feb. 12th. The wounds were sloughing; and the removal of the crushed fingers was advised, but resisted.

Feb. 14th, The injured fingers were amputated at the metacarpal joints.

Feb: 16th. The patient was restless, and passed a bad night.

Fob. 17th. He took morphine, and slept well. He had had some slight stiffness about his neck on the 11th, and was therefore ordered to continue the quinine, with a plentiful allowance of tender mutton and sherry.

Feb. 23rd. I was requested to go out to see him in the evening; and learned that, on the two previous nights, he had slept very little; that he had intense pain in the hand and arm, for which symptoms his medical attendant had prescribed calomel and opium freely and frequently; and that he had complained this afternoon of stiffness of his jaw. When I asked to see his tongue, he could not open his mouth sufficiently to protrude it. He complained of pain and difficulty in swallowing; the angles of his mouth were drawn down, giving him the peculiar physiognomy of tetanus; his articulation was indistinct; and he had also convulsive twitchings of the affected arm. He was ordered to have a strong solution of hydrochlorate of morphine applied to the wounds, which were clean, and discharging abundantly; also to take every four hours a draught containing three grains of sulphate of quinine and one drachm of sulphate of magnesia (amounting to eighteen grains of quinine in the day), and a pill containing half a grain of extract of belladonna; a dose of morphine every night; and a continued liberal allowance of beef-tea, sherry, and mutton, when he could manage it.

From this date (Feb. 23rd) to March lst, the progress of the disorder seemed to be satisfactorily arrested; but, as the trismus persisted, the dose of extract of belladonna was then again increased. He had been taking one grain; he was now ordered a grain and a half every four hours, which dose he began to take on the following day. The quinine was also directed to be increased gradually up to six grain doses every four hours. Under this treatment, the trismus steadily subsided. The belladonna very soon produced symptoms of its peculiar narcotism (dilated pupils, visual illusions, with confusion of head, etc.), and was left off. The quinine was continued to the 22nd of March. The wound by that time was healed, or nearly so; and the only remaining symptom of tetanus was an altered physiognomy, the angles of the mouth being drawn down; and this, the writer thinks, has not even now entirely disappeared.

This patient was one of a family, in more than one member of which cerebral affections, with mental alienation, had been witnessed. It was therefore feared that this accident might lead to tetanic affections; and the quinine treatment was directed to this indication from within a day or two of the receipt of injury.

Case II. February 12th, 1855. Mr. P., a respectable tradesman, aged 25 years, single, and previouly in good health, but liable to slight dyspeptic disorder, met with a gun accident, by which the index finger of his right hand was so much shattered, as to require immediate amputation. The accident occurred in the third week of January 1865.

I found him with rigidity of his facial muscles; the jar was almost fixed; the abdominal muscles were also rigid; there were twitchings of the muscles of the arm and hand, with cramp of the muscles of the right thigh and leg. The pulse was weak, 120-130; he had no sleep; the tongue was furred; he had obstinate constipation. He was ordered to take at bed-time twenty minims of liquor opii sedatirus; to be repeated if necessary ; to take two-grain doses of extract of belladonna every six hours, and four-grain doses of quinine every four hours; also to have beef tea and sherry.

February 16th. Urine and fæces were obstinately rotained. The catheter was for several days regularly introduced; and a variety of enemata employed containing spirit of turpentine, croton oil, etc.; but on three separate occasions an enema consisting of a drachm of chloroform, with starch, appeared to act like a charm. The medical gentleman in attendance with me suggested and employed this remedy, and is very confident of its efficacy. Probably the introduction of belladonna, mixed with lard, within the anus-recommended, I think, in cases of another kind by anus-recommended, I by him to succeed-would relax the perineal muscles, on which both the constipation and retention of urine are supposed to depend.

February 21st. The progress of the tetanic disorder appeared to be completely arrested, but no material improvement was yet obtained.

The dose of extract of belladonna was increased to three grains, but with a longer interval-twelve hours: the grains, was also directed to be taken in six-grain doses quinine was also directed to be hours (thirty-six grains daily) given with sulphate of magnesia, and dilute sulphuric acid, as in the former case.

February 26th. The symptoms had all very much subsided; the bowels and bladder acted spontaneously; the mouth could be opened much more widely; the twitching and spasm of the limbs had abated; he slept well; the andse was under 90 , and stronger. The belladonna had been pushed to narcotism, and suspended. The dose of quinine was now diminished, as also the previous allowance of wine. The wound was all but healed.

March lst. I took my leave.

Rarch 1st. The narrative of these cases, thus too shortly detailed from the case-book, would appear incomplete without some reflections by way of commentary, and of comout some refiections be statements contained in treatises on parison, too, with the statem suggested view of pathology, founded on two or three cases, can assume but the form of conjecture.

In the three cases mentioned in this paper, the ages were severally 17,25 , and 28 . All were males, single, and proviously in good health. All had injury of small extremities; the first a crush of the great toe in a steam engine; the second a crush of three fingers of left hand; the third a shattered wound of index finger of right hand. In all three, the wound was open, and not jet in a healthy condition; so there could be no pinching of nerves "by contraction of cicatrix." (Trnka and Travers.)

In the case last detailed, the pulse, on my first visit, was 120-130; a rate which, according to Parry's dogma, rendered the prognosis highly unfavourable, but happily contradicted by the result.

"Warm weather" and " a warm climate" have been severally supposed to predispose the wounded to tetanus. In the first case, tetanus set in on April 3rd; in the second on February 23rd; and in the third on February 12th; and certainly without an elevated, or even moderate, temperature in any of the three.

" Moist situations" are also said to create a predisposition to tetanus; and with this opinion, our cases are uniformly compatible. The first, though it occurred in a remarkably compatible. The frst, surrounded by a continually moist atmosphere; for it was on the premises of a brewery doing a considerable business,-premises, therefore, never froe from a floor and an atmosphere thoroughly moist, and perhape 
something more. The second occurred at a residence, as ometre stated, surrounded by water meadow; and the thind occurred in the same parish as the second, only a mile lower down the same river. And it may be well to mention, that I have had another case of trismus in this same parish, but of a hysterical and not traumatic nature.

Facts, rightly interpreted, must ever comport with true science; and the object of the writer in detailing, thus imperfectly, these cases of tetanus, is the hope that they may assist in justifying the science of medicine. Quinine is the scientific means of treatment for disorders having an intermittent action; and belladonna is again the scientific means of overcoming natural and, it would seem also, morbid muscular contraction. It may be fairly inferred, from the progress of these cases, that the quinine arrested the diseased action; but in both the cases, the spasms only yielded when the fully accumulated effect of the belladonna was evinced in its peculiar narcotism.

And here the writer would suggest two things on the subject of the use of belladonna: 1st, to try the efficacy of every sample of the extract, by applying a solution to the conjunctiva, in order to see its power over the pupil; and, 2ndly, in the sleeplessness and irritability of tetanus, not to rely upon this narcotic for procuring sleep, which it does sometimes, but only seldom, produce. In these cases, the liquor opii sedativus, or morphine, was of signal service in promoting sleep.

In the three cases here narrated, in the case of hysterical trismus alluded to, and in another similar case in a valley a fow miles further in the same direction, the circumstances permit the conjecture that malaria might have predisposed, where moisture was undoubtedly in action. Malaria has been demonstratively proved to exist in many places not visited by any well defined type of intermittent fever; and if we suppose that in a brewery, where the vegetable matters and fermentable substances abound,-in a state, too, of warmth and moisture,-malaria may be in existence, as it has been proved to be in Covent Garden, and other like places, then we cannot exclude the notion of malaria having predisposed all the fire patients, here spoken of, to their attacks of tetanus and trismus. With such a conjecture, having some little analogical support, the treatment by quinine, in the successful cases, is in perfect harmony.

Dorchester, July 1855.

\section{$\checkmark$ \\ REPORT ON AN INTESTINAL CONCRETION FROM A HORSE.}

By GEORGE RIGDEN, Esq., Surgeon to the Canterbury Dispensary.

[Read before the South Eastern Branch, June 27th, 1855.]

THE concretion represented in the accompanying woodcuts was taken from the large intestine of a horse; but in consequence of the person who opened the body and found it not being acquainted with the anatomy of the parts, I have not been able to ascertain the exact position in which it was lodged; indeed, but for its weight and size, it might have escaped notice. It evidently consists of a large portion of animal mixed with earthy matter, deposited in layers. I had expected to find the earthy matter composed principally of lime; but from an analysis made in this city of some of the powder produced by its division, I am assured that lime does not enter into its composition, but that the inorganic matter is composed of an ammoniaco-magnesian phosphate. Its weight when first removed was two pounds four ounces; it measured six inches in its longest diameter; and had six distinct prolongations or angles running from its centre or nucleus, which was formed by a nail or long piece of iron. The layers of the concretion were nearly black and buff-coloured, with a peculiarly bright shining surface.

The horse had been in the possession of its last owner (a carrier) for at least twenty Jears, and had not been known to suffer from illness or other inconvenience from the concretion. It had been fed upon split besns, dried and green meat, but not upon bran; and was only destroyed in consequence of its extreme age.

The concretion was purchased by Mr. Alderman Masters of the person who removed it, upon the condition of its being placed in the Canterbury museum.

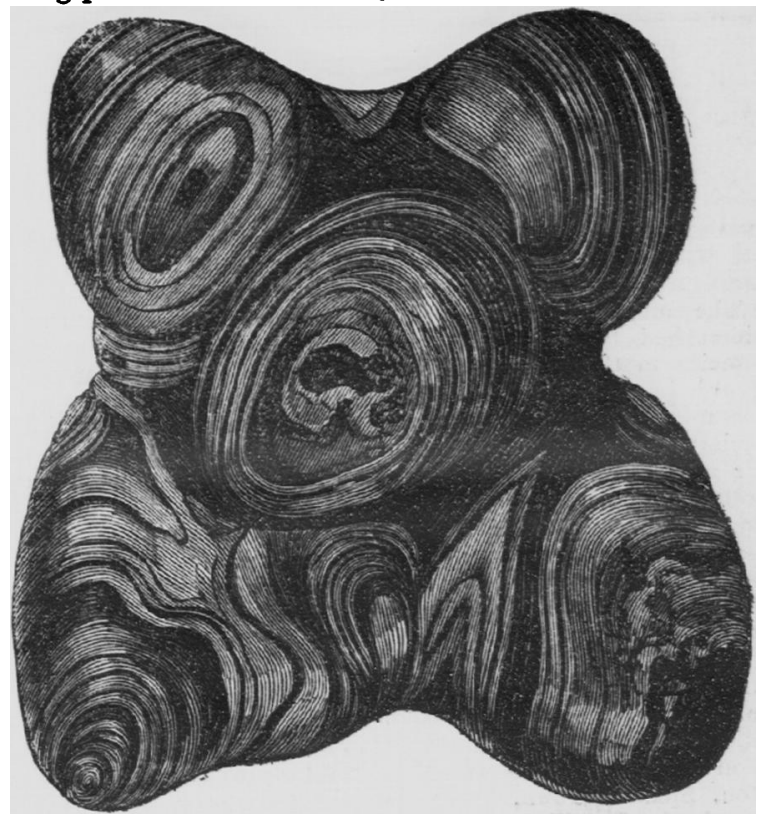

A riew of the concretion, shering tive of its angles.

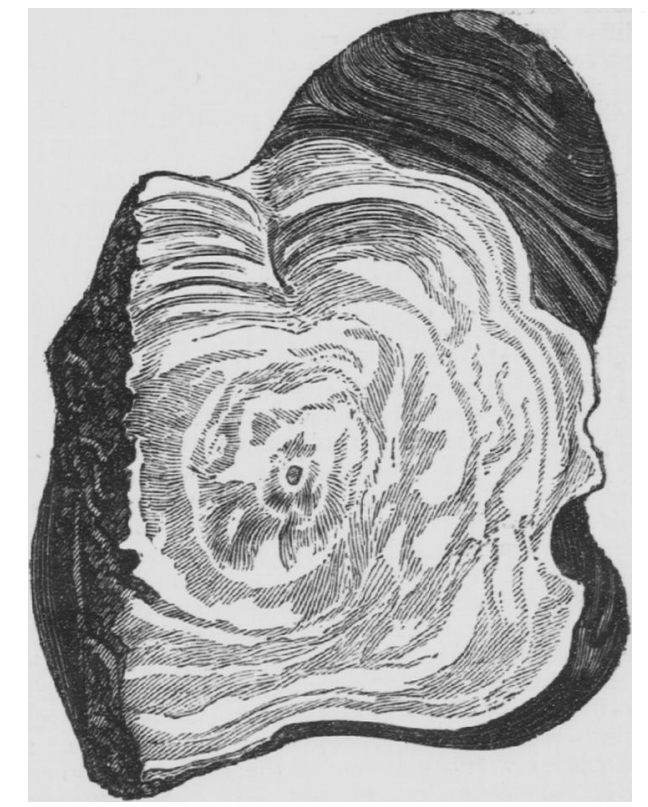

A section of the concretion showing, in the centre, the nail or piece of iron which probubly formed the original nucleus.

It is not uncommon to find concretions of the like or a similar nature in the intestines of horses, particularly in those belonging to millers, or that have been fed principally upon bran; but they are not usually so large, and are generally of a more globular form. The great peculiarities of this concretion appear to be its large size, its angular form, and its bright and shining surface; this lest property appears to have been acquired by the liquid matters constantly passing between its angles, as the extreme 